\title{
Psoriasis in obesity: comparison of serum levels of leptin and adiponectin in obese subjects - cases and controls*
}

\author{
Nádia Couto Bavoso ${ }^{1}$, Jackson Machado Pinto ${ }^{1}$, Maria Marta Sarquis Soares ${ }^{2}$, Michelle dos Santos \\ Diniz ${ }^{1}$, Antônio Lúcio Teixeira Júnior ${ }^{3,4}$
}

DOI: http:/ / dx.doi.org/10.1590/abd1806-4841.20197716

\begin{abstract}
BACKGROUND: Psoriasis and obesity are somewhat related to a low-grade systemic inflammatory response.
Овјестіves: To determine leptin and adiponectin levels in psoriasis patients compared to control patients matched for weight. Methods: A case-control study was performed, evaluating 113 psoriasis patients and 41 controls with other dermatologic diseases.

RESULTS: The prevalence of obesity was 33\% in cases and $21.9 \%$ in controls. All evaluated comorbidities were more prevalent among cases. When stratified by weight, the comorbidities were more frequent in overweight patients. We found no correlation between being overweight $(p=0.25)$, leptin $(p=0.18)$ or adiponectin $(p=0.762)$ levels and psoriasis severity. When overweight cases and controls were compared, we found differences in the adiponectin values $(p=0.04)$. The overweight cases had lower adiponectin levels than the overweight controls. We found no differences in the leptin dosage between cases and controls. The overweight cases had higher leptin values than the normal weight cases $(\mathrm{p}<0.001)$.

StUdy Limitations: Several patients used systemic anti-inflammatory medication.

Conclusions: The prevalence of obesity among psoriasis cases (33\%) was higher than in the general population (17.4\%). We did not find any correlation between severity of psoriasis and inflammatory cytokines and the condition of being overweight. The overweight cases had lower values of adiponectin than the overweight controls. It seems, therefore, that there is a relationship between adiponectin and psoriasis, but this relationship depends on the presence of obesity.
\end{abstract}

Keywords: Adiponectin; Leptin; Obesity; Psoriasis

\section{INTRODUCTION}

Psoriasis is a dermatological disease that affects $2-3 \%$ of the global population. It presents a genetic basis but is affected strongly by environmental factors. The cutaneous lesions show elevated levels of pro-inflammatory cytokines, and a low-grade systemic inflammatory response is believed to occur. ${ }^{1}$ The pro-inflammatory molecules released during chronic inflammation can favor the pre- sence of one or more comorbidities, including diabetes mellitus, dyslipidemia, acute myocardial infarction and obesity. ${ }^{2-5}$

There is an increasing number of epidemiological studies on the association between psoriasis and obesity. The mechanism responsible for this association is not yet understood, though it is probably multifactorial, involving genetic and environmental fac-

\footnotetext{
Received 04 October 2017.

Accepted 21 February 2018.

* Work conducted at the Santa Casa de Misericórdia de Belo Horizonte, Belo Horizonte (MG), Brasil.

Financial Support: Fundação de Amparo à Pesquisa do Estado de Minas Gerais (FAPEMIG).

Conflict of Interests: None.

Dermatology Service, Santa Casa de Misericórdia de Belo Horizonte, Belo Horizonte (MG), Brazil.

Department of Clinical Medicine, Universidade Federal de Minas Gerais, Belo Horizonte (MG), Brazil.

Discipline of Neurology, Faculdade de Medicina, Universidade Federal de Minas Gerais, Belo Horizonte (MG), Brazil.

Interdisciplinary Laboratory of Medical Investigation, Faculdade de Medicina, Universidade Federal de Minas Gerais, Belo Horizonte (MG), Brazil.
}

MAILING AdDRESS:

Nádia Couto Bavoso

E-mail: nadiabavoso@hotmail.com

C2019 by Anais Brasileiros de Dermatologia 
tors and inflammatory mediators. ${ }^{6,7}$ It is believed that the cytokines leptin and adiponectin, known to be involved in obesity, are also related to psoriasis. ${ }^{8-10}$

Leptin is a pro-inflammatory cytokine derived from adipocytes, and its circulating levels are correlated directly with body fat mass. ${ }^{11}$ Leptin acts on the hypothalamus to suppress appetite, increase caloric expenditure and regulate body weight. It could be expected, therefore, that obese people have low leptin, since they present weight gain and increased appetite. However, obesity is associated with hyperleptinemia, but also with leptin resistance., ${ }^{8,11-13}$

In addition to being a pituitary regulator of food intake, body weight and fat storage, leptin plays an important role in inflammatory processes through regulation of the expression of other cytokines that modulate the balance of Th1 and Th2 cells. It is postulated that the high leptin levels in obese patients may aggravate psoriasis through the release of inflammatory mediators that act directly on the cutaneous lesions. Furthermore, an increase in systemic inflammation can worsen the general condition of the patient who, typically, already has several other inflammatory comorbidities associated with psoriasis., ${ }^{2,14}$ This fact could contribute even further to increasing the cardiovascular risk observed in these patients. ${ }^{15,16}$ Recently, hyperleptinemia was proposed to be associated with psoriasis, independent of sex or of conventional cardiovascular risk factors such as obesity. ${ }^{17,18}$

Adiponectin, in turn, is a cytokine produced by adipose tissue at levels inversely proportional to one's body mass index (BMI) and waist-hip ratio. It induces the release of pro-inflammatory cytokines IL-1 and IL-10 and inhibits the cytokines IL- 6 and TNF- $\alpha$. Adiponectin is known for its anti-inflammatory, antidiabetic and cardioprotective effects. ${ }^{19}$

Obesity, especially visceral adiposity, promote the state of hyperadiponectinemia, which results in greater cardiovascular risk. ${ }^{20-23}$ Some studies found that patients with psoriasis have low levels of plasma adiponectin, which possibly contributes to the worsening of the skin lesions. ${ }^{24}$ Apparently, adiponectin and TNF- $\alpha$ are negatively correlated. ${ }^{25,26}$

The existing literature so far supports the connection between psoriasis and obesity, with emphasis on the influence of the inflammatory cytokines. Apparently, the cytokines involved in obesity are also involved in the physiopathology of psoriasis. Whether this involvement is relevant, and how it manifests, is not yet known. Most published studies emphasize the levels of inflammatory substances such as TNF- $\alpha$, PCR and IL- $6 .{ }^{27}$ Few works have analyzed the inflammatory cytokines involved in obesity, such as leptin and adiponectin. Studies that clarify whether a concrete relationship exists between psoriasis and obesity are important, since they provide health professionals with an approach to systemic inflammation that is unified and targeted rather than compartmentalized and, often, incomplete. The association between psoriasis and obesity, though already described, needs to be examined more thoroughly in an attempt to understand which physiopathological mechanisms are involved in this process.

The objective of this work is to evaluate the prevalence of obesity among the patients with psoriasis at the outpatient Dermatology Clinic of Santa Casa de Belo Horizonte. It is believed that this prevalence is higher than among the general population, as the scientific literature suggests an association between these two comorbidities. Other aims of this study are to compare the serum levels of leptin and adiponectin in patients with psoriasis and controls paired by weight, in addition to determining the prevalence of obesity and overweight in patients with psoriasis. We also intended to evaluate whether hyperleptinemia and hypoadiponectinemia are associated with psoriasis, independent of concomitant obesity or not, and to evaluate whether the levels of leptin and adiponectin and the degree of obesity are correlated with the severity of psoriasis.

\section{METHODS}

We conducted a case-control study that evaluated 113 patients with psoriasis and 41 controls with other dermatological complaints, paired by weight. The cases were submitted to clinical assessment of psoriasis severity using the instrument Psoriasis Area and Severity Index (PASI), and the case and control patients' anthropometric measurements of height, weight and abdominal circumference were taken. All of the patients responded to questionnaires about quality of life and were instructed to complete a clinical history form. Comorbidities were assessed based on patients' self-reporting or on their use of specific medication, such as antihypertensives, metformin, insulin, statins or fibrates. We tested for the presence of systemic arterial hypertension (SAH), diabetes mellitus (DM) and dyslipidemia. We examined the cases of patients using systemic medications to treat psoriasis. Blood was collected from all patients, and the level of cytokines in the plasma was measures using the ELISA method (RED Systems). The work was approved by the institution's research ethics committee, under the number 094/2011. In the univariate analysis, Pearson's chi-squared test or Fisher's exact test were used to compare the categorical variables, and the Mann-Whitney non-parametric test was used to analyze the numerical variables. In the multivariate analysis, the binary logistic regression model was used. After fitting the final model, the adjusted odds ratio (OR) estimate was evaluated, with a respective confidence interval of 95\% (IC95\%). All the analyses were stratified between the cases and controls and were performed in the software SPSS version 15.0.

\section{RESULTS}

The average age among the cases was 55.3, ranging from 18 to 87 years. The average age among the controls was 39.9, ranging from 19 to 65 years. The controls were younger than the cases $(\mathrm{p}<0.001)$.

In terms of sex, the case group presented more women than men, and the control group had more men. Among the cases, 56.6\% were female and $43.4 \%$ were male. Among the controls, $46.3 \%$ were women and $53.7 \%$ were men.

Of the 113 patients assessed as cases, $61.6 \%$ presented were overweight (defined as $25 \mathrm{~kg} / \mathrm{m}^{2} \leq \mathrm{BMI}<30 \mathrm{~kg} / \mathrm{m}^{2}$ ) and $33 \%$ were obese (defined as BMI $\geq 30 \mathrm{~kg} / \mathrm{m}^{2}$ ). The highest BMI recorded was $45 \mathrm{~kg} / \mathrm{m}^{2}$, and the minimum was $17.1 \mathrm{~kg} / \mathrm{m}^{2}$. The average BMI of the cases was $28.2 \mathrm{~kg} / \mathrm{m}^{2}( \pm 5.7)$.

Of the 41 controls evaluated, $73.2 \%$ were overweight and $21.9 \%$ were obese; maximum BMI was $44.2 \mathrm{~kg} / \mathrm{m}^{2}$ and the mini- 
mum was $17.8 \mathrm{~kg} / \mathrm{m}^{2}$. The average BMI of the controls was $27.2 \mathrm{~kg} /$ $\mathrm{m}^{2}( \pm 4.3)$.

Therefore, we observed that the cases presented more obesity than the controls.

The cases present greater prevalence of all evaluated comorbidities when compared to the controls. SAH was found in $48.7 \%$ of the cases and in $26.8 \%$ of the controls ( $p=0.015)$. DM was found in $19.5 \%$ of the cases and in $2.4 \%$ of the controls $(p=0.009)$. Dyslipidemia was found in $24.8 \%$ of the cases and in $2.4 \%$ of the controls ( $p$ $=0.002)$ (Table 1$)$.

In the case group, we found no relationship between BMI and the severity of psoriasis (Table 2).

\begin{tabular}{|c|c|c|c|}
\hline & Cases $(n=113)$ & $\begin{array}{l}\text { Controls } \\
(\mathrm{n}=41)\end{array}$ & $\begin{array}{c}P \\
\text { value }\end{array}$ \\
\hline \multicolumn{4}{|l|}{ Sex } \\
\hline Male & $49(43.4 \%)$ & $22(53.7 \%)$ & \multirow[t]{2}{*}{$0.257^{*}$} \\
\hline Female & $64(56.6 \%)$ & $19(46.3 \%)$ & \\
\hline \multicolumn{4}{|c|}{$\begin{array}{l}\text { Excess weight } \\
\left(\mathrm{BMI} \geq 25 \mathrm{~kg} / \mathrm{m}^{2}\right)\end{array}$} \\
\hline No & $43(38.4 \%)$ & $11(26.8 \%)$ & \multirow[t]{2}{*}{$0.185^{*}$} \\
\hline Yes & $69(61.6 \%)$ & $30(73.2 \%)$ & \\
\hline \multicolumn{4}{|c|}{ Comorbidities } \\
\hline \multicolumn{4}{|c|}{ SAH } \\
\hline No & $58(51.3 \%)$ & $30(73.2 \%)$ & \multirow[t]{2}{*}{$0.015^{*}$} \\
\hline Yes & $55(48.7 \%)$ & $11(26.8 \%)$ & \\
\hline \multicolumn{4}{|l|}{ DM } \\
\hline No & $91(80.5 \%)$ & $40(97.6 \%)$ & \multirow[t]{2}{*}{$0.009^{*}$} \\
\hline Yes & $22(19.5 \%)$ & $1(2.4 \%)$ & \\
\hline \multicolumn{4}{|c|}{ Dyslipidemia } \\
\hline No & $85(75.2 \%)$ & $40(97.6 \%)$ & \multirow[t]{2}{*}{$0.002^{*}$} \\
\hline Yes & $28(24.8 \%)$ & $1(2.4 \%)$ & \\
\hline
\end{tabular}

${ }^{*}$ Chi-squared test
We found no relationship between the PASI and the evaluated cytokines in the case group, with and without current systemic treatment. No correlation was observed between excess weight ( $p$ $=0.25)$, leptin $(\mathrm{p}=0.18)$ or adiponectin $(\mathrm{p}=0.762)$ and psoriasis severity in the case group. The only correlation found was between leptin and adiponectin (Spearman -0.1987; p = 0.0151) when we assessed all patients collectively (Table 3).

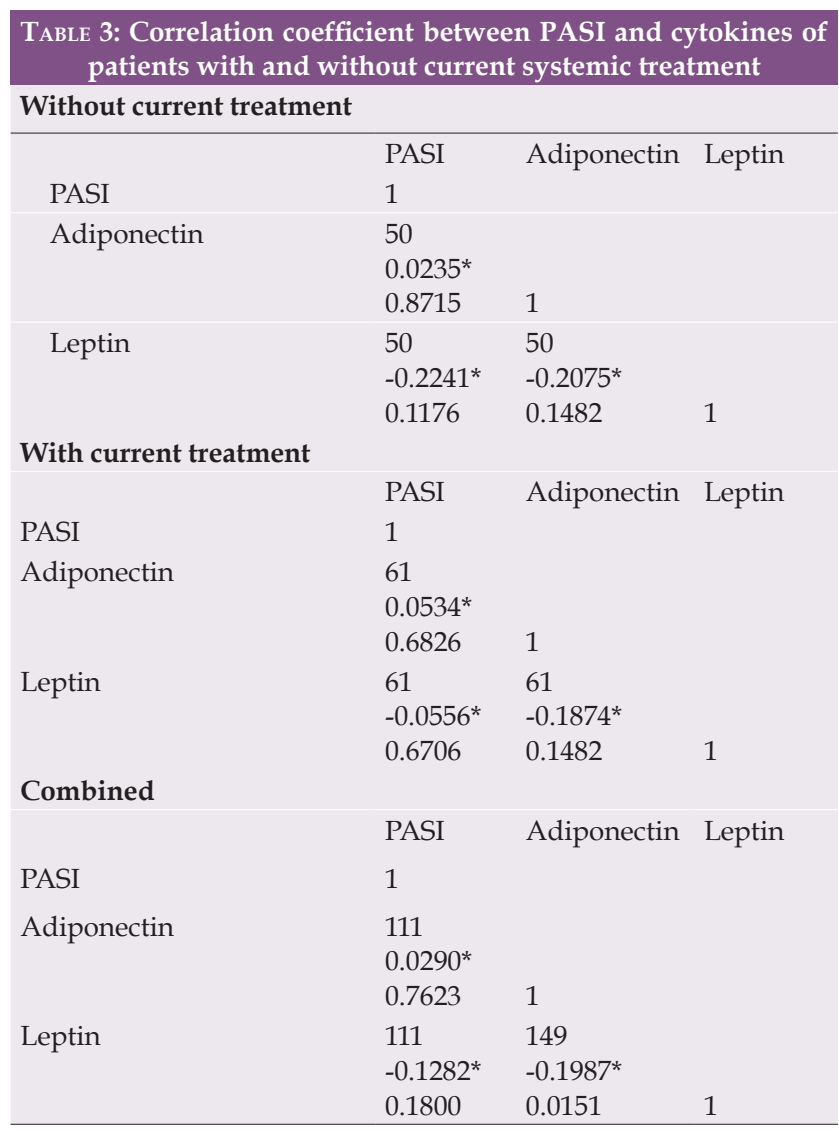

*Spearman's correlation

TABLE 2: Univariate analysis evaluating psoriasis characteristics in relation to excess weight (cases)

\begin{tabular}{|c|c|c|c|c|c|}
\hline Cases & & Diagnosis time & PASI & BSA & DLQI \\
\hline \multirow[t]{4}{*}{ Without excess weight $\left(\mathrm{BMI}<25 \mathrm{~kg} / \mathrm{m}^{2}\right)$} & $\mathrm{n}$ & 43 & 43 & 43 & 53 \\
\hline & Mean & 13.3 & 5.1 & 11.4 & 3.8 \\
\hline & Standard deviation & 10.5 & 9.0 & 20.5 & 4.6 \\
\hline & $50^{\text {th }}$ Percentile & 10.0 & 2.4 & 4.0 & 2.0 \\
\hline \multirow[t]{5}{*}{ With excess weight (BMI $\geq 25 \mathrm{~kg} / \mathrm{m}^{2}$ ) } & $\mathrm{n}$ & 69 & 69 & 69 & 98 \\
\hline & Mean & 10.7 & 4.8 & 10.6 & 4.1 \\
\hline & Standard deviation & 8.7 & 6.0 & 14.8 & 4.9 \\
\hline & $50^{\text {th }}$ Percentile & 10.0 & 3.1 & 5.0 & 3.0 \\
\hline & P-value e** $^{* *}$ & 0.287 & 0.250 & 0.500 & 0.434 \\
\hline
\end{tabular}

*** Mann-Whitney test 
When comparing the excess-weight cases and controls, we found a difference in the values of adiponectin $(p=0.04)$. The excess-weight cases had lower values than the excess-weight controls. We found no difference in the leptin levels between these cases and controls $(\mathrm{p}=0.11)$ (Table 4).

Among the cases, the excess-weight patients had higher leptin levels than the normal-weight patients $(p<0.001)$ (Table 5).

In the multivariate analyses, we found no correlation between cytokines and the other variables.

\section{DISCUSSION}

We found that the prevalence of obesity in two groups (33\% of cases and $21.9 \%$ of controls) is considerably higher than the prevalence among the general Brazilian population, which is $18.9 \%$ according to the epidemiological data of the VIGITEL (Surveillance of Risk Factors and Protection for Chronic Diseases by Telephone Inquiry) for 2016. Several well-conducted studies have reported an increase in the prevalence of obesity among patients with psoriasis. Of these studies, we highlight the works of Kaye et al. (2008) and Neimann et al. (2006), conducted in the United Kingdom, which assessed 44,164 and 131,560 individuals, respectively. ${ }^{28-31}$

When we examined only the cases, we found that the leptin levels were higher in excess-weight patients compared to normal-weight patients. This finding supports the data in the literature, as

\begin{tabular}{|c|c|c|c|}
\hline Cases $\mathrm{x}$ controls & & $\begin{array}{l}\text { Adiponectin } \\
(\mathrm{pg} / \mathrm{mL})\end{array}$ & $\begin{array}{l}\text { Leptin } \\
\text { (pg/mL) }\end{array}$ \\
\hline \multirow{4}{*}{$\begin{array}{l}\text { Excess-weight } \\
\text { controls } \\
\left(\mathrm{BMI} \geq 25 \mathrm{~kg} / \mathrm{m}^{2}\right)\end{array}$} & $\mathrm{n}$ & 29 & 29 \\
\hline & Mean & 45034.7 & 1693.78 \\
\hline & Standard deviation & 4708.4 & 469.56 \\
\hline & $50^{\text {th }}$ Percentile & 43963.2 & 1896.8 \\
\hline \multirow{4}{*}{$\begin{array}{l}\text { Excess-weight } \\
\text { cases } \\
\left(\mathrm{BMI} \geq 25 \mathrm{~kg} / \mathrm{m}^{2}\right)\end{array}$} & $\mathrm{n}$ & 68 & 68 \\
\hline & Mean & 43041.5 & 1863.5 \\
\hline & Standard deviation & 5027.6 & 362 \\
\hline & $50^{\text {th }}$ Percentile & 42992.0 & 1930.5 \\
\hline$P$-value & & 0.04 & 0.11 \\
\hline
\end{tabular}

TABLE 5: Univariate analysis of cytokine levels in relation to excess weight (cases)

\begin{tabular}{|c|c|c|c|}
\hline Cases & & $\begin{array}{l}\text { Adiponectin } \\
\text { (pg/mL) }\end{array}$ & $\begin{array}{l}\text { Leptin } \\
\text { (pg/mL) }\end{array}$ \\
\hline \multirow{4}{*}{$\begin{array}{l}\text { Without excess } \\
\text { weight } \\
\left(\text { BMI < } 25 \mathrm{~kg} / \mathrm{m}^{2}\right)\end{array}$} & $\mathrm{n}$ & 42 & 42 \\
\hline & Mean & 44089.0 & 1466.6 \\
\hline & Standard deviation & 6837.9 & 625.9 \\
\hline & $50^{\text {th }}$ Percentile & 43891.7 & 1745.6 \\
\hline \multirow{4}{*}{$\begin{array}{l}\text { With excess } \\
\text { weight } \\
\left(\mathrm{BMI} \geq 25 \mathrm{~kg} / \mathrm{m}^{2}\right)\end{array}$} & $\mathrm{n}$ & 68 & 68 \\
\hline & Mean & 43041.5 & 1863.5 \\
\hline & Standard deviation & 5027.6 & 362.0 \\
\hline & $50^{\text {th }}$ Percentile & 42992.0 & 1930.5 \\
\hline$P$-value ${ }^{* * *}$ & & 0.433 & $<0.001$ \\
\hline
\end{tabular}

***Mann-Whitney test hyperleptinemia has been associated with obesity and psoriasis in several cases. ${ }^{32-34}$

We did not find hypoadiponectinemia in the excess-weight cases compared to normal-weight cases, contrary to the current findings in the literature. . $^{35,36}$

We were unable to confirm the association between BMI and psoriasis severity found by Murray et al., who conducted a study with 88 cases in outpatient treatment for psoriasis and with same-sex siblings as controls. The study correlated BMI with psoriasis severity and found a positive association..$^{31,37,38}$

In a comparison of excess-weight cases and controls, we found lower values of adiponectin in patients with psoriasis that in the controls; however, these case patients did not present higher levels of leptin than the controls. In 2008, Takahashi et al. conducted a study in Japan involving 122 patients with psoriasis and 78 healthy controls. Serum TNF- $\alpha$, leptin and adiponectin were measured in these patients, and the data were correlated with the severity of psoriasis, measured with the PASI instrument. The leptin levels were higher, and the adiponectin levels lower, in patients with psoriasis than in the healthy controls. Furthermore, the adiponectin levels negatively correlated with the PASI, while the leptin levels tended to correlate positively. ${ }^{39}$

Unlike Chen et al., when we compared normal-weight cases and controls, we found no differences in leptin and adiponectin values. In 2008, Chen et al. conducted a study of 77 patients with psoriasis diagnoses and 81 controls paired by sex and age. Obesity and hypertension were significantly prevalent in the psoriasis patients. In the multivariate analysis, hyperleptinemia was found in psoriasis patients independent of concomitance with obesity. ${ }^{40}$

In 2013, Zhu et al. conducted a meta-analysis that failed to find a clear association between adiponectin levels and BMI and found no evidence of a relationship between adiponectin levels and psoriasis severity. ${ }^{36}$ These same authors conducted a meta-analysis, also in 2013, to examine the relationship between leptin and psoriasis. Eleven studies were included, with a total of 773 psoriasis patients and 570 controls. In the stratified analysis, significant differences in the leptin levels between patients and controls were found only in serum samples and not in plasma samples. The leptin levels in psoriasis patients were higher than in control patients. ${ }^{41}$

Our study was conducted at a state dermatology referral center. Referral services usually bring together the most serious cases of a disease and, though difficult, can be reliably used to represent or generalize the population of that particular disease.

Although the groups were not comparable with respect to some variables in the univariate analysis, mainly in relation to age and comorbidities, this limitation was overcome with the multivariate analysis.

Our study did not evaluate patients under 18 years of age, which, considering that psoriasis has a bimodal incidence peak, resulted in a failure to evaluate a good portion of the affected population. Another important point to consider is the use of systemic anti-inflammatory medications by most of our patients. Recent studies show that patients taking systemic medications present significant alterations in their levels of inflammatory cytokines. ${ }^{33,42,43}$ These studies show that the use of systemic anti-inflammatory drugs to treat 
psoriasis lowers leptin levels and elevates serum adiponectin levels. In our study, we found patients taking methotrexate (38 patients), acitretin (12 patients), prednisone (two patients), PUVA (two patients), adalimumab (three patients) and etanercept (four patients).

We should add that, as a considerable proportion of our psoriasis patients were using systemic medications (54.9\%), the PASI of these patients was found to be lower than would be expected if they were not using systemic medications. As we found no relationship between cytokine levels and psoriasis severity, we attributed this fact to the use of systemic anti-inflammatory medications.

Cytokine levels were measured only once, because the high number of patients involved in this study made a second measurement financially difficult. The large number of individuals did enable us, however, to compare the samples more reliably. In addition, the ELISA method has high sensitivity and strict quality control.

\section{CONCLUSIONS}

The prevalence of obesity among patients with psoriasis (33\%) was higher than among the general Brazilian population $(18.9 \%)$. We found no correlation between disease severity and inflammatory cytokines or excess weight. Hyperleptinemia is associated with obesity, but we could not prove an independent association with psoriasis.

Hypoadiponectinemia is associated with psoriasis, but this relationship is dependent on the presence of excess weight.

The levels of leptin and adiponectin did not correlate with the severity of psoriasis. We found no relationship between BMI and psoriasis severity. $\square$

\section{ACKNOWLEDGEMENT}

We thank FAPEMIG for the financial support.

\section{REFERENCES}

1. Reich K. The concept of psoriasis as a systemic inflammation: implications for disease management. J Eur Acad Dermatol Venereol. 2012;(Suppl 2):S3-11.

2. Boehncke S, Thaci D, Beschmann H, Ludwig RJ, Ackermann H, Badenhoop K. Psoriasis patients show signs of insulin resistance. $\mathrm{Br} J$ Dermatol. 2007:157:1249-51.

3. Ayala F, Ayala F. Clinical aspects and comorbidities of psoriasis. J Rheumatol Suppl. 2009;83:19-20.

4. Farley E, Menter A. Psoriasis: comorbidities and associations. G Ital Dermatol Venereol. 2011;146:9-15.

5. Al-Mutairi N, Al-Farag S, Al-Mutairi A, Al-Shiltawy M. Comorbidities associated with psoriasis: an experience from the Middle East. J Dermatol. 2010;37:146-55

6. Bremmer S, Van Voorhees AS, Hsu S, Korman NJ, Lebwohl MG, Young M, et al. Obesity and psoriasis: from the Medical Board of the National Psoriasis Foundation. J Am Acad Dermatol. 2010:63:1058-69.

7. Duarte GV, Follador I, Cavalheiro CM, Silva TS, Oliveira Mde F. Psoriasis and obesity: literature review and recommendations for management. An Bras Dermatol. 2010;85:355-60.

8. Linkinghub.elsevier.com [Internet]. Mechanick Jl, Zhao S, Garvey WT. Leptin, An Adipokine With Central Importance in the Global Obesity Problem. Glob Hear. [cited 2017 Dec 21]. Available from: http://linkinghub.elsevier.com/retrieve/pii/ S2211816017301199

9. Ricci R, Bevilacqua F. The potential role of leptin and adiponectin in obesity: A comparative review. Vet J. 2012;191:292-8.

10. Gerdes S, Rostami-Yazdi M, Mrowietz U. Adipokines and psoriasis. Exp Dermatol. 2011;20:81-7.

11. Farooqi IS, O'Rahilly S S. 20 YEARS OF LEPTIN: Human disorders of leptin action. J Endocrinol. 2014;223:T63-70.

12. Xue K, Liu H, Jian Q, Liu B, Zhu D, Zhang $M$, et al. Leptin induces secretion of pro-inflammatory cytokines by human keratinocytes in vitro--a possible reason for increased severity of psoriasis in patients with a high body mass index. Exp Dermatol. 2013;22:406-10.

13. Farr OM, Gavrieli A, Mantzoros CS. Leptin applications in 2015: what have we learned about leptin and obesity? Curr Opin Endocrinol Diabetes Obes. 2015:22:353-9.
14. Machado-Pinto J, Diniz M dos S, Bavoso NC. Psoriasis: new comorbidities. An Bras Dermatol. 2016;91:8-14

15. Ryan C, Menter A. Psoriasis and cardiovascular disorders. G Ital Dermatol Venereol. 2012;147:179-87

16. Warnecke C, Manousaridis I, Herr R, Terris DD, Goebeler M, Goerdt S, et al. Cardiovascular and metabolic risk profile in German patients with moderate and severe psoriasis: a case control study. Eur J Dermatol. 2011:21:761-70.

17. Johnston A, Arnadottir S, Gudjonsson JE, Aphale A, Sigmarsdottir AA, Gunnarsson $\mathrm{SI}$, et al. Obesity in psoriasis: leptin and resistin as mediators of cutaneous inflammation. Br J Dermatol. 2008;159:342-50.

18. Kyriakou A, Patsatsi A, Sotiriadis D, Goulis DG. Serum Leptin, Resistin, and Adiponectin Concentrations in Psoriasis: A Meta-Analysis of Observational Studies. Dermatology. 2017;233:378-389

19. Nigro E, Scudiero 0, Monaco ML, Palmieri A, Mazzarella G, Costagliola C, et al. New Insight into Adiponectin Role in Obesity and Obesity-Related Diseases. Biomed Res Int. 2014;2014:658913.

20. Rasouli N, Kern PA.. Adipocytokines and the metabolic complications of obesity. J Clin Endocrinol Metab. 2008:(11 Suppl 1):S64-73

21. Gerdes S, Mrowietz U. Comorbidities and psoriasis. Impact on clinical practice. Hautarzt. 2012:63:202-13.

22. Shibata S, Tada Y, Hau C, Tatsuta A, Yamamoto M, Kamata M, et al. Adiponectin as an anti-inflammatory factor in the pathogenesis of psoriasis: induction of elevated serum adiponectin levels following therapy. Br J Dermatol. 2011;164:667-70.

23. Ellulu MS, Patimah I, Khaza'ai H, Rahmat A, Abed Y. Obesity and inflammation: the linking mechanism and the complications. Arch Med Sci. $2017 ; 13: 851-63$

24. Campanati A, Ganzetti G, Giuliodori K, Marra M, Bonfigli A, Testa R, et al. Serum levels of adipocytokines in psoriasis patients receiving tumor necrosis factor- $\alpha$ inhibitors: results of a retrospective analysis. Int J Dermatol. 2015;54:839-45

25. Frühbeck G, Catalán V, Rodríguez A, Gómez-Ambrosi J. Adiponectin-leptin ratio: A promising index to estimate adipose tissue dysfunction. Relation with obesityassociated cardiometabolic risk. Adipocyte. 2018;7:57-62

26. Balsan GA, Vieira JL, Oliveira AM, Portal VL. Relationship between adiponectin, obesity and insulin resistance. Rev Assoc Med Bras (1992). 2015;61:72-80. 
27. Link.springer.com [Internet]. Engin A. The Pathogenesis of Obesity-Associated Adipose Tissue Inflammation. In: Engin AB, Engin A, editors. Obesity and Lipotoxicity. Cham: Springer International Publishing; 2017. p. 221-45 [cited 2018 Jan 5]. Available from: http://ink.springer.com/10.1007/978-3-319-48382-5 9

28. Kaye JA, Li L, Jick SS. Incidence of risk factors for myocardial infarction and other vascular diseases in patients with psoriasis. Br J Dermatol. 2008;159:895-902

29. Neimann AL, Shin DB, Wang X, Margolis DJ, Troxel AB, Gelfand JM. Prevalence of cardiovascular risk factors in patients with psoriasis. J Am Acad Dermatol. 2006;55:829-35

30. Jacobi A, Langenbruch A, Purwins S, Augustin M, Radtke MA. Prevalence of Obesity in Patients with Psoriasis: Results of the National Study PsoHealth3. Dermatology. 2015;231:231-8.

31. Fleming P, Kraft J, Gulliver WP, Lynde C. The Relationship of Obesity With the Severity of Psoriasis: A Systematic Review. J Cutan Med Surg. 2015;19:450-6.

32. Eder L, Jayakar J, Pollock R, Pellett F, Thavaneswaran A, Chandran V, et al. Serum adipokines in patients with psoriatic arthritis and psoriasis alone and their correlation with disease activity. Ann Rheum Dis. 2013;72:1956-61.

33. Ozdemir M, Yüksel M, Gökbel H, Okudan N, Mevlitoğlu I. Serum leptin, adiponectin, resistin and ghrelin levels in psoriatic patients treated with cyclosporin. J Dermatol. 2012:39:443-8.

34. Wolk K, Sabat R. Adipokines in psoriasis: An important link between skin inflammation and metabolic alterations. Rev Endocr Metab Disord. 2016;17:305317.
35. Shibata S, Tada Y, Hau CS, Mitsui A, Kamata M, Asano Y, et al. Adiponectin regulates psoriasiform skin inflammation by suppressing IL-17 production from $\gamma \delta$-T cells. Nat Commun. $2015 ; 6: 7687$.

36. Zhu KJ, Shi G, Zhang C, Li M, Zhu CY, Fan YM. Adiponectin levels in patients with psoriasis: a meta-analysis. J Dermatol. 2013;40:438-42.

37. Murray ML, Bergstresser PR, Adams-Huet B, Cohen JB.. Relationship of psoriasis severity to obesity using same-gender siblings as controls for obesity. Clin Exp Dermatol. 2009;34:140-4.

38. Sobhan M, Farshchian M. Associations between body mass index and severity of psoriasis. Clin Cosmet Investig Dermatol. 2017 Nov 24;10:493-498.

39. Takahashi H, Tsuji H, Takahashi I, Hashimoto Y, Ishida-Yamamoto A, lizuka H. Plasma adiponectin and leptin levels in Japanese patients with psoriasis. $\mathrm{Br}$ Dermatol. 2008;159:1207-8.

40. Chen YJ, Wu CY, Shen JL, Chu SY, Chen CK, Chang YT et al. Psoriasis independently associated with hyperleptinemia contributing to metabolic syndrome. Arch Dermatol. 2008:144:1571-5.

41. Zhu KJ, Zhang C, Li M, Zhu CY, Shi G, Fan YM. Leptin levels in patients with psoriasis: a meta-analysis. Clin Exp Dermatol. 2013;38:478-83.

42. Pina T, Genre F, Lopez-Mejias R, Armesto S, Ubilla B, Mijares V, et al. Relationship of Leptin with adiposity and inflammation and Resistin with disease severity in Psoriatic patients undergoing anti-TNF-alpha therapy. J Eur Acad Dermatol Venereol. 2015;29:1995-2001.

43. Campanati A, Ganzetti G, Giuliodori K, Marra M, Bonfigli A, Testa R, et al. Serum levels of adipocytokines in psoriasis patients receiving tumor necrosis factor- $\alpha$ inhibitors: results of a retrospective analysis. Int J Dermatol. 2015;54:839-45.

Statistical analysis; Approval of the final version of the manuscript; Conception and planning of the study; Elaboration and writing of the manuscript; Obtaining, analyzing and interpreting the data; Effective participation in research orientation; Intellectual participation in propaedeutic and/or therapeutic conduct of the cases studied; Critical review of the literature; Critical review of the manuscript

Maria Marta Sarquis Soares

iD ORCID 0000-0002-0847-7060

Approval of the final version of the manuscript; Conception and planning of the study; Obtaining, analyzing and interpreting the data; Intellectual participation in propaedeutic and/or therapeutic conduct of the cases studied; Critical review of the manuscript

Michelle dos Santos Diniz $\quad$ (iD) ORCID 0000-0002-9259-0807

Statistical analysis; Approval of the final version of the manuscript; Conception and planning of the study; Elaboration and writing of the manuscript; Obtaining, analyzing and interpreting the data; Effective participation in research orientation; Intellectual participation in propaedeutic and/or therapeutic conduct of the cases studied; Critical review of the literature; Critical review of the manuscript

Antônio Lúcio Teixeira Júnior

ORCID 0000-0002-9621-5422

Obtaining, analyzing and interpreting the data

How to cite this article: Bavoso NC, Pinto JM, Soares MMS, Diniz MS, Teixeira Jr AL. Psoriasis in obesity: comparison of serum levels of leptin and adiponectin in obese subjects - cases and controls. An Bras Dermatol. 2019;94(2):192-7. 